\title{
Fuzzy tuning approach for adaptive exponential smoothing used in short-term forecasts
}

\author{
Kısa dönemli tahminlerde kullanılan uyarlamalı üstel düzleştirme için \\ bulanık ayarlama yaklaşımı
}

\author{
Yunus BIÇEN $1^{*}$ \\ 1Electronics and Automation Department, Düzce Vocational School of Higher Education, Düzce University, Düzce, Turkey. \\ yunusbicen@gmail.com
}

Received/Geliş Tarihi: 20.02.2016, Accepted/Kabul Tarihi: 01.09.2016

* Corresponding author/Yazıșilan Yazar

doi: $10.5505 /$ pajes.2016.69335

Research Article/Araștırma Makalesi

\begin{abstract}
Adaptive smoothing methods were suggested to improve forecast results on the characteristic changes of time series. The existing adaptive smoothing methods have been diversified over the years. Many of them are comprised of complicated logical or mathematical propositions for improving forecast accuracy, which are very different from the original simple method called Trigg and Leach method. A new method named Fuzzy Tuning Exponential Smoothing is introduced in this paper introduces. This method is successful in improving the forecast accuracy, especially for the time series including level shift or level shift with outlier deflection. The empirical application carried out on 'The M2-Competition Time Series'. The statistical analysis results demonstrate that the method outperforms classical adaptive smoothing method in terms of forecasting accuracy. In addition, the proposed method is relatively simple compared to other advanced adaptive methods.
\end{abstract}

Keywords: Adaptive exponential smoothing, Deflection, Forecasting, Fuzzy logic, Level shift, Time series

\section{Introduction}

Exponential smoothing and its derivatives have been commonly used by researcher dealing with the forecasting process covering a widespread area from engineering to social sciences for a long time [1]-[5]. Theoretically, these forecasts are carried out from an exponentially weighted average of past observations. These methods can be investigated in two parts as adaptive and non-adaptive approaches. Adaptive exponential smoothing technique introduced by Trigg \& Leach in 1967 (T-L) is pioneer work in the adaptive approaches and it is preferred for its intelligibility [6]. Adaptive smoothing approach is presented to overcome insensitivity problems on the time series changes (these are level shifts, ramp shifts, and etc.) as a result of certain events such as economic, politic, natural, technological changes [7],[8]. However, it is reported that some in cases this technique delivers unstable forecasts compared to non-adaptive smoothing techniques [9]-[11] Therefore, researchers have strived to develop effective adaptive smoothing techniques and consequently, the numbers of these techniques have increased over the years.

In classical adaptive approach, smoothing parameter is adaptively adjusted depending on the last forecasting error magnitude to track time series changes and this process is performed on simple exponential smoothing (SES) [8],[9]. Also, several adaptive techniques considering trend and seasonality are developed such as Evolutionary Operation (EVOP) by Chow and its extended version Self-Adaptive Forecasting Technique (SAFT) by Roberts \& Reed [12],[13].
Öz Uyarlamalı düzleștirme metotları zaman serilerinin karakteristik değişimleri üzerindeki tahmin sonuçlarını iyileştirmek için önerilmișlerdir. Zaman içerisinde var olan uyarlamalı düzleștirme metotları çeşitlenmiştir. Birçoğu Trigg \& Leach olarak isimlendirilen orijinal basit metottan çok farklı olup, doğruluğu artırmak için karmaşık mantıksal veya matematiksel önermeler içermektedir. Bu makalede Bulanık Ayarlamalı Üstel Düzleștirme olarak isimlendirilen yeni bir metot sunulmaktadır. Bu metot özellikle seviye kayması veya seviye kaymasıyla beraber aykırı sapmaların bulunduğu zaman serileri için tahmin doğruluğunun iyileștirilmesinde bașarılıdır. Ampirik uygulama 'The M2-Competition Time Series' üzerinde gerçekleștirilmiştir. Istatistiksel analiz sonuçları tahmin doğruluğu açısından bu metodun klasik uyarlamalı üstel düzleştirme metodunu geride bıraktığını göstermektedir. Buna ek olarak önerilen metot diğer gelişmiş uyarlanabilir metotlarla karşılaştırıldığında oldukça basittir.

Anahtar kelimeler: Uyarlamalı üstel düzleștirme, Sapma, Tahmin, Bulanık mantık; Seviye kayması; Zaman serileri

SAFT makes the best forecast by using heuristic technique that tries each combination of level, trend, and seasonality smoothing factors to reach the lowest mean absolute percentage error (MAPE) value for each period [14]. This methodology has been modified by Mentzer several times, using T-L approach for the smoothing factors [14],[15]. Thus, the technique has become more sensitive towards to the end of the series. However, it is widely accepted in the literature that only the level smoothing factor should be adaptive without other parameters belonging to trend and seasonality to prevent instability on the forecast and that is why the SES has been generally preferred [9]. There are some conservative models developed by Whybark, Dennis, which smoothing factor changes according to the control limits [16],[17]. The other one developed by Rao and Shapiro which uses the spectrum of the time series to determine level smoothing factor [18]. Kalman filter has been used as an alternative model to adjust to the parameter of SES. However, this model has some limitations and also the empirical evidence is not enough for verifying an ideal approach [9]. Pantazopoulos and Pappis have proposed a simpler method (named as P-P in this paper) which adapts to the level smoothing factor dividing absolute value of the two steps ahead forecast error by the one step ahead error [19]. However, empirical results indicate that smoothing factor often takes a value of 1 [20]. Another method is Taylor's smooth transition exponential smoothing (STES) which enables a smoothing parameter to be adapted to a logistic function of user-specified variables [9],[21]. The origin of STES is based on the smooth transition generalized auto 
regressive conditional heteroskedastic (GARCH) models and the numerical simulation results are satisfactory for this model [20],[21]. The drawback of the STES is that modelfitting is needed to estimate some parameters used in the function [20]. A recent study by Monfared et al., revised simple exponential smoothing (RSES) is introduced as an alternative method to recognize non-stationary level shifts in the time series and to adopt the weight coefficients accordingly [8]. This method does not require transitional variables or any judgmental information. However, there is no comparative analysis with other adaptive methods. Apart from these methods, some hybrid approaches have been proposed to set smoothing factors adaptively, using some expert system and algorithms [22]-[26]. In practice, these approaches have achieved successful results in industry where they have been used, but they have stayed private due to the difficulty of application. It is obvious that the developments carried out on the adaptive versions become complicated and difficult to understand in time. Easily applicable methods are still being preferred in industry.

A new method named fuzzy tuning exponential smoothing (FTES) is evolved taking into account the above assessments in this study. This method has three main features. The first is being simple and straightforward. The second is quickly responding to the series changes especially in level shifts, and the last feature is preventing the deviation effects of outlier changes. In the following section, the theoretical base of FTES method is primarily described. In Section 3, the discussions of forecasting results on numerical examples are presented and the performance of the method is evaluated in terms of validity. Finally, a conclusion is given in Section 4.

\section{Theoretical statement of the FTES method}

The proposed method includes a fuzzy logic controller to set the smoothing factor. It is known that the adaptive smoothing factor can be any rational number between 0 and 1 band ranges. However, the success of the proposed method depends on the determination of ideal adaptive smoothing factors minimizing the future forecast errors. The advantage of the fuzzy logic approach is also being capable of including experience by using linguistic expressions in the decisionmaking process. Thus, the adaptive forecasting process, normally complex quantitative functions are simplified with the linguistic terms qualitatively. FTES method is comprised of three simple parts as shown in Figure 1. In the first part, the variance-sensitive variables called $\varphi_{\mathrm{t}}$ in period $(t)$, and $\varphi_{\mathrm{t}-1}$ in period ( $\left.t-1\right)$ are determined. The second part is fuzzy logic controller which sets the smoothing factor $\alpha_{t}$ and the last part is the adaptive forecasting based on a SES equation as given:

$$
F_{t+1}=\alpha S_{t}+(1-\alpha) F_{t}
$$

As well known, in this static equation, the smoothing factor $\alpha$ is a constant selected optimally by minimizing the sum of squares errors or any suitable error function for the next forecasts [15]. $F_{t+1}$ is the next period forecast and $S_{t}$ is the observed value. However, the smoothing factor should be renewed for each period in the adaptive version $\left\{\forall \alpha_{t}: \alpha_{t} \in\right.$ $\left.Q^{+}, 0 \leq \alpha_{t} \leq 1\right\}$ as defined in equation 2 .

$$
F_{t+1}=\alpha_{t} S_{t}+\left(1-\alpha_{t}\right) F_{t}
$$

In FTES method, the smoothing factor $\alpha_{t}$ determined by multiinput, single-output (MISO) fuzzy controller. The inputs called variance-sensitive variables $\varphi_{t}$ and $\varphi_{t-1}$ are updated for each period and defined as the following formulas:

$$
\begin{gathered}
\varphi_{t}=\frac{\left|\sigma_{t}^{2}-\sigma_{t-1}^{2}\right|}{\overline{\sigma_{t}^{2}}} \\
\varphi_{t-1}=\frac{\left|\sigma_{t-1}^{2}-\sigma_{t-2}^{2}\right|}{\overline{\sigma_{t-1}^{2}}}
\end{gathered}
$$

Where, $\sigma_{t}^{2}$ denotes the population variance, $\overline{\sigma_{t}^{2}}$ is the variance average of the whole series up to $(t)$ time. The population consists of the $t$ elements $S_{1} \ldots S_{t} \therefore$ the average is $\mu=\frac{1}{t} \sum_{i=1}^{t} S_{i}$ and the variance equation is given by

$$
\sigma_{t}^{2}=\frac{\sum_{i=1}^{t}\left(S_{i}-\mu\right)^{2}}{t}
$$

In this study, the variance calculations are performed as the following form;

$$
\sigma_{t}^{2}=\left[\frac{\left(S_{t}-\mu_{t}\right)^{2}+\left(S_{t-1}-\mu_{t}\right)^{2}+\left(S_{t-2}-\mu_{t}\right)^{2}}{3}\right]
$$

In this form, the last moving 3 observed values are taken into account in the series and thereby the reduction of the variance changing in time is prevented. Where $\mu_{t}$ is the moving trioaverage and it is computed as $\mu_{t}=\frac{1}{3} \sum_{i=t-2}^{t} S_{i}$ for each period. The variance-sensitive variable $\varphi_{\mathrm{t}}$ changes depending on whether the series is wavy or not. If a level shift or an outlier deflection has been occurred in the series, $\varphi_{\mathrm{t}}$ increases. Theoretically, $\varphi_{\mathrm{t}}$ can reach very high values for some peak points according to the characteristics of the series. However, in normal conditions, $\varphi_{\mathrm{t}}$ circulates around the average of the variance-sensitive variable $\overline{\varphi_{\mathrm{t}}}$, generally. The limits of the input membership functions are defined as multiples of average of the variance-sensitive variable $\overline{\varphi_{t}}$ for both inputs. These input limit values can be continually updated in each cycles if desired. But it is not practical to do this without big character change in the series. Therefore, $\overline{\varphi_{\mathrm{t}}}$ value could be selected fixed average level according to the time series characteristic and updated occasionally at certain intervals. The most important point to be considered in this process is that the peak points are not included in the value of average in order to avoid deviations from the mean. The input membership functions are composed of four intervals called low, mean, high and peak as shown in Figure 2(a) The limits of the output membership functions created for the smoothing factor are defined as fixed four intervals called v-low, low, high, and v-high in the range of $[0,1]$ as shown in Figure $2(b)$.

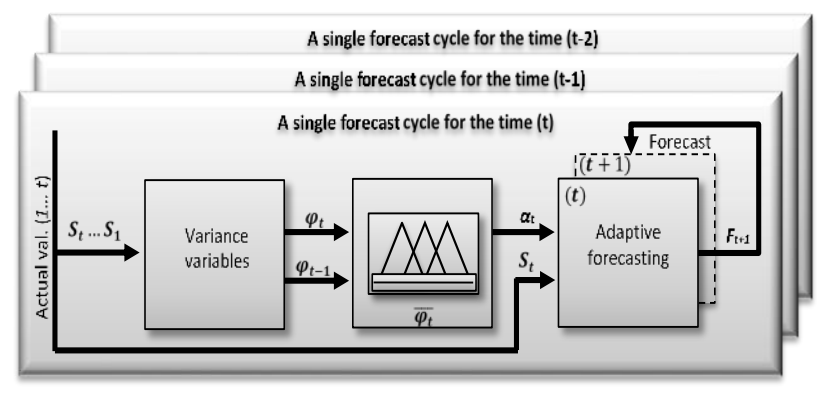

Figure 1: FTES method forecasting cycles. 
The variance-sensitive variable $\varphi_{\mathrm{t}}$ takes smaller value for stationary or low volatility characteristics of the series. In these cases, it is reasonable to select low $\alpha_{t}$ values. If the volatility rises, $\varphi_{\mathrm{t}}$ takes higher values with $\alpha_{t}$ to catch significant changes in the series. In some cases, nonpermanent very high leaps (spike, peak, etc.) may occur in the time series under abnormal conditions. For example, the majority of the electricity spot-price series are non-stationary and they include spikes with seasonal variations [27]-[29]. However these spikes are not permanent unlike level shift. Therefore, the forecasting errors are increased in these events. To overcome of this problem by the proposed method, when such a situation occurs, the $\alpha_{t}$ value is set as v-low instead of just setting v-high value. In the next step, it is observed that whether the situation is permanent or not, by checking the current $\varphi_{\mathrm{t}}$ and the previous $\varphi_{\mathrm{t}-1}$ values. If the level of the current $\varphi_{\mathrm{t}}$ are large $\left(\sim 9 \overline{\varphi_{\mathrm{t}}}<\varphi_{\mathrm{t}}\right)$ the adaptive smoothing factor $\alpha_{t}$ should be selected as small value (close to 0 ), again. But, how much $\alpha_{t}$ would be close to 0 is determined by the size of the $\varphi_{\mathrm{t}-1}$ value. If the peak situation is not permanent, this time the adaptive smoothing factor $\alpha_{t}$ should be selected according to the value of current $\varphi_{t}$. Through this simple logic, very large forecast errors arising from abnormal situations are automatically eliminated. In order to perform these processes, 7 rules are defined in the fuzzy rule base respectively and the surface graphic belonging to changes of the smoothing factor $\alpha_{t}$ depending on the input variables is shown in Figure 3, as follows:

\section{Verifying of the proposed method}

\subsection{Graphical validation}

In this section, the validity of FTES method is demonstrated by using two time series. The first series includes level shifts and it is obtained a reference called M2-Competition (M2C88, 2 monthly series) [30]. The second series is actually similar to the first series except one peak point (formed on the same series). Figure 4(a) shows forecasts belonging to the first series for all methods. Smoothing parameter $\alpha_{t}$ takes different values for the adaptive methods except for the SES in each period as shown in Figure 4(b), 4(c) and 4(d) respectively. The diversity of the smoothing parameter changes for the FTES method is less than the other adaptive methods and it is stable at the point where no more change in the series. When a remarkable increase or decrease occurs in the series, it varies depending on fuzzy controller which is sensitive to the variance changes. However, the response speed of the FTES method is much faster than the T-L, except in cases of peak. Similarly, the response speed of the P-P is fast, but it is not stable due to the lack of variation range evaluation. The superiority of the FTES method is better understood when APE changes are investigated with other methods as shown in Figure 4(f), 4(g), 4(h) and 4(i) respectively. For the first series (level shift only), APE changes of the SES method are lower from the adaptive methods up to (point 56). However, it is quite normal, because the smoothing factor has been determined to be optimal value using the past data up to (point 56). During the level shift, APE changes of the FTES method are lower than the other methods. For the second series (level shift with outlier deflection), the advantage of the FTES method is revealed more clearly when the last group of figures located in Figure 5 is examined. During the outlier deflection (at point 83), all APE results are similar for all methods. But from that point (point 84 and after), APE results of the FTES method is significantly lower compared to the other methods as shown in Figure 5(f). The outlier deflection occurring at any point of the series has an inevitable impact on the estimation based on P-P method as shown in Figure 5(g). FTES method detects the outlier deflections which do not conform to the character of the series and reduces the forecast error; it adjusts the smoothing parameter $\alpha_{t}$ a small value for the next forecast as shown in Figure 5(b). The smoothing parameter $\alpha_{t}$ at this point takes as 0.2 value for the FTES method while it takes as 0.55 value for the T-L method and 1 value for the P-P method. Even if there are small errors caused by the outlier deflections, these errors are attempted to be minimized by the nature of the FTES method.

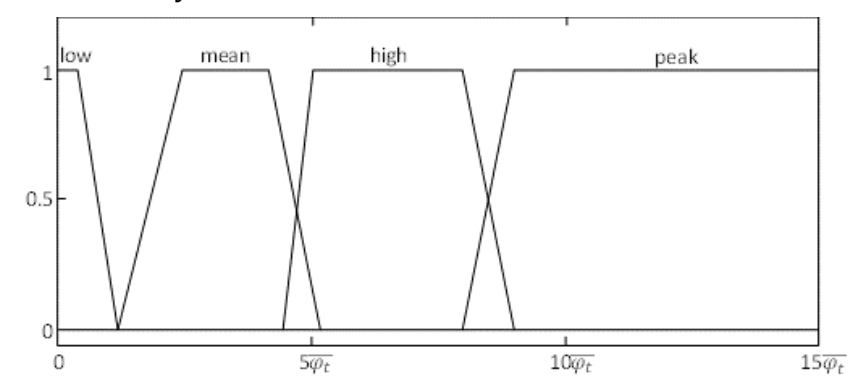

(a)

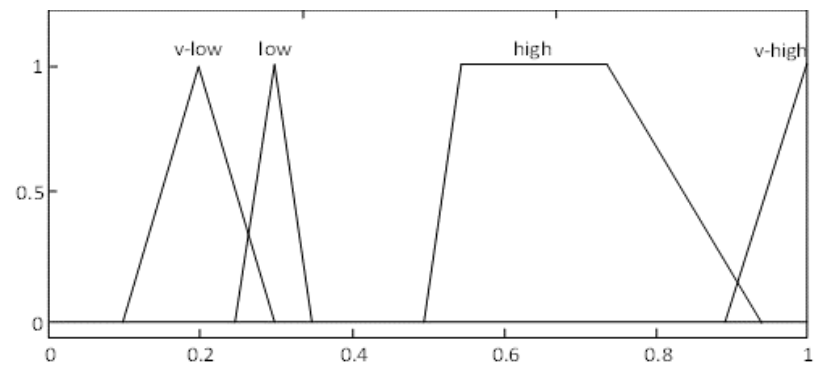

(b)

Figure 2: (a): Input membership functions and

(b): Output membership functions.
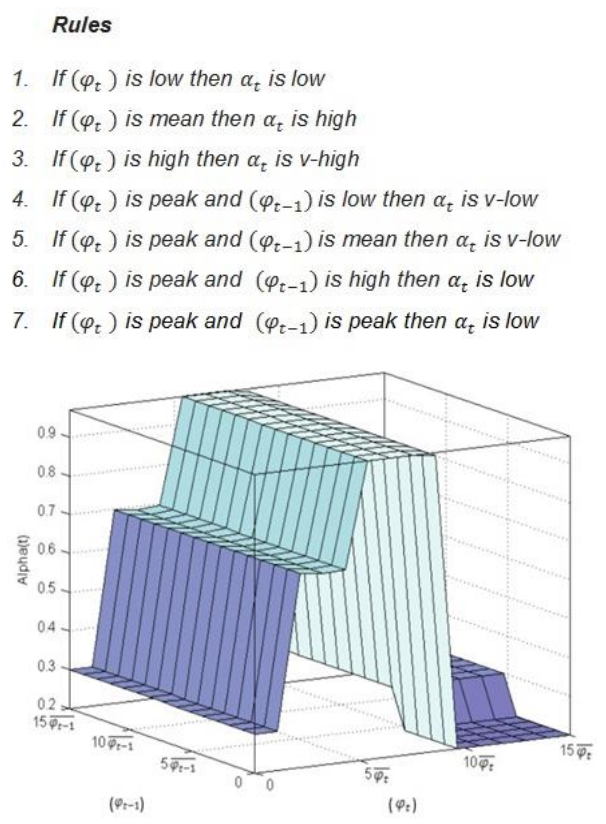

Figure 3: Fuzzy rules with surface appearance. 


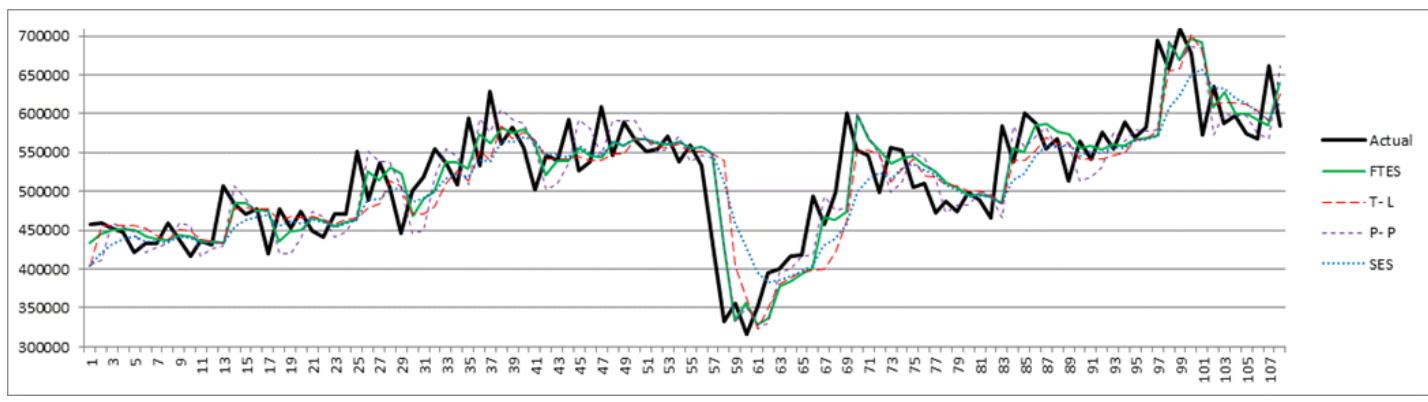

(a)

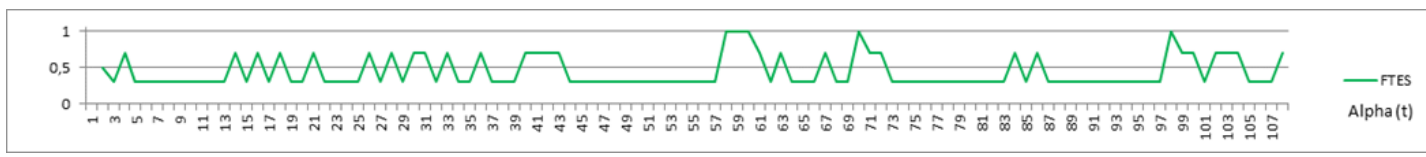

(b)

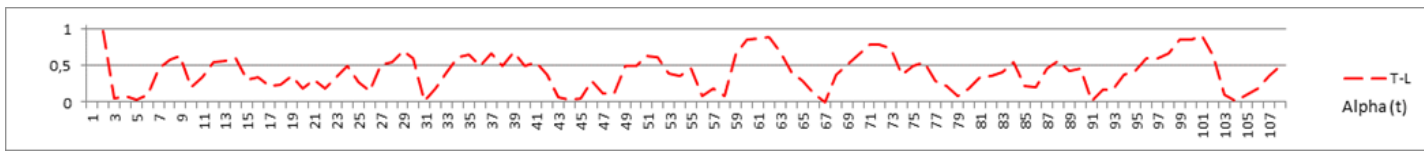

(c)

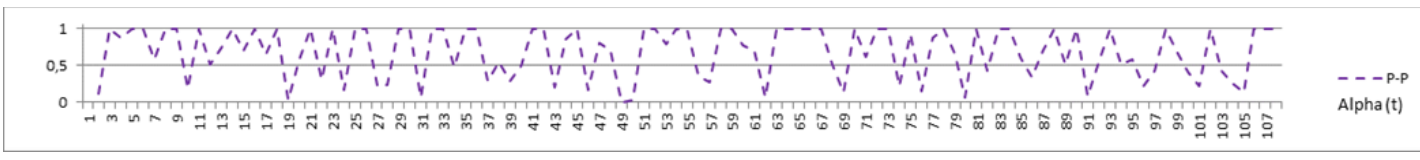

(d)

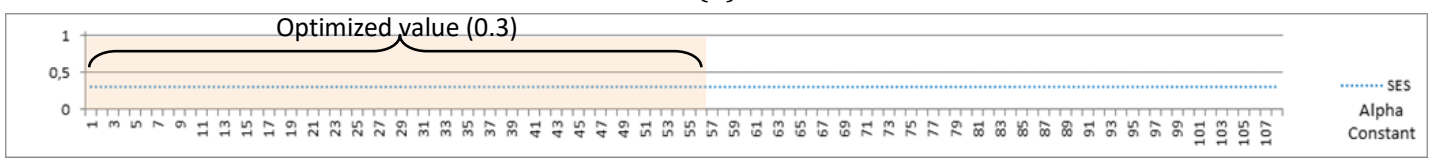

(e)

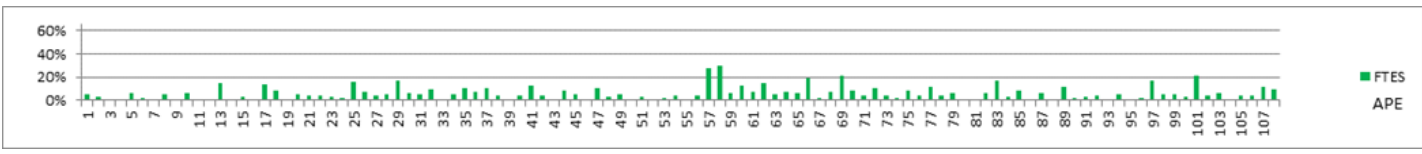

(f)

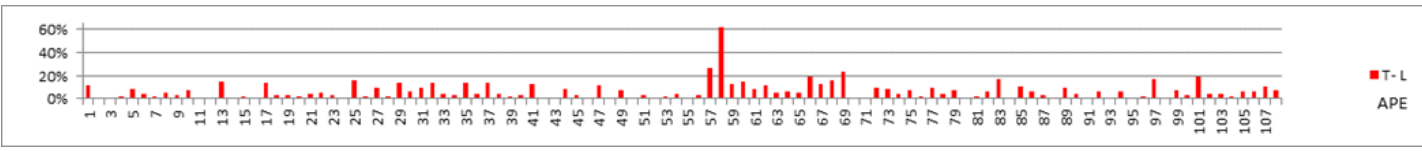

(g)

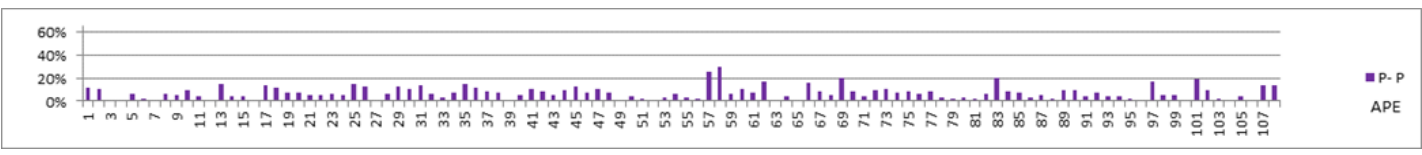

(h)

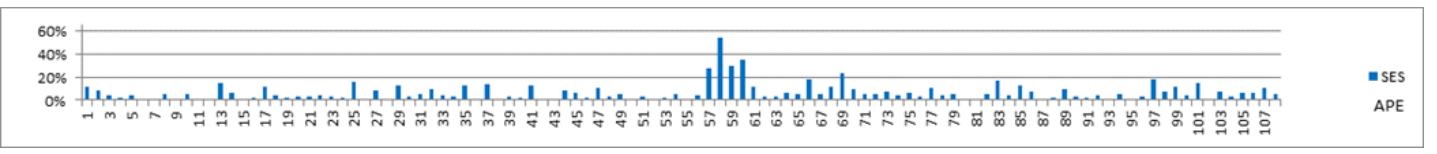

(i)

Figure 4: (a): Comparative forecasts produced by all methods named as FTES, T-L, P-P and SES, respectively. These forecasts are carried out for only level shift in the series, (b): Smoothing parameter $\alpha_{t}$ changes for the FTES method, (c): Smoothing parameter $\alpha_{t}$ changes for the T-L method, (d): Smoothing parameter $\alpha_{t}$ changes for the P-P method, (e): Optimized and fixed smoothing parameter $\alpha$ for SES method for the whole series and this value obtained using the past data of up to 56 points, (f): Absolute percentage error (APE) changes at each forecast point for the FTES method, (g): APE changes at each forecast point for the T-L method, (h): APE changes at each forecast point for the P-P method, (i): APE changes at each forecast point for the SES method. 


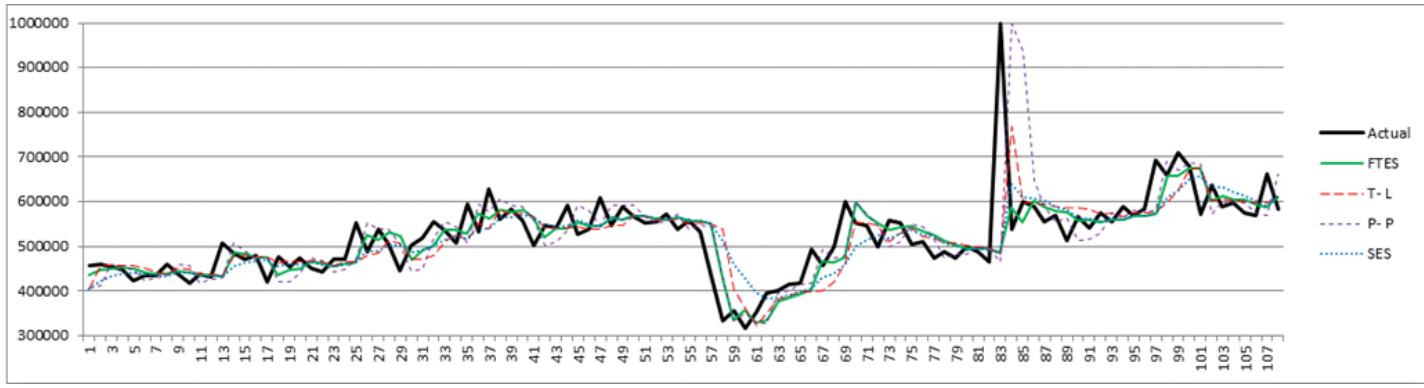

(a)

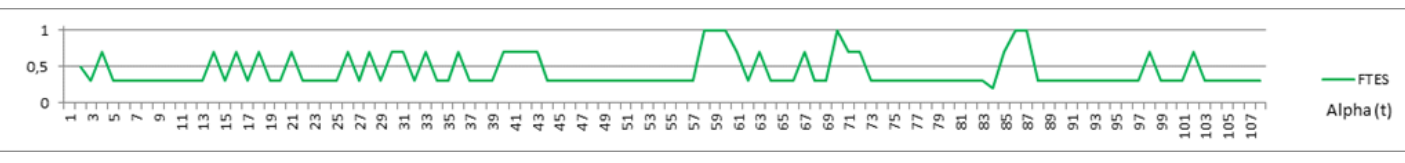

(b)

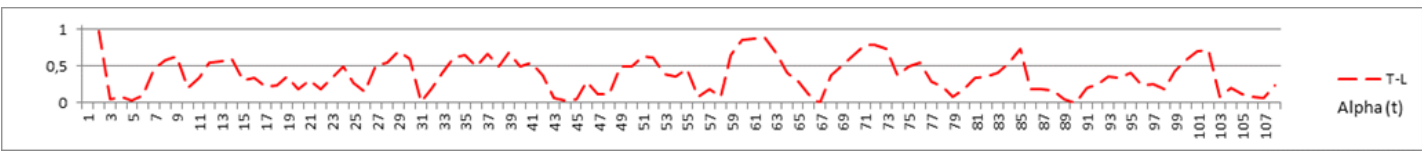

(c)

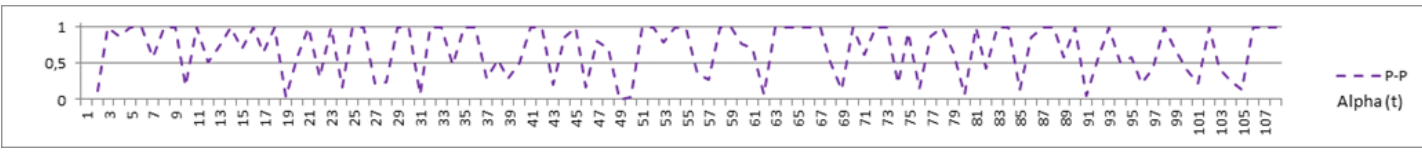

(d)

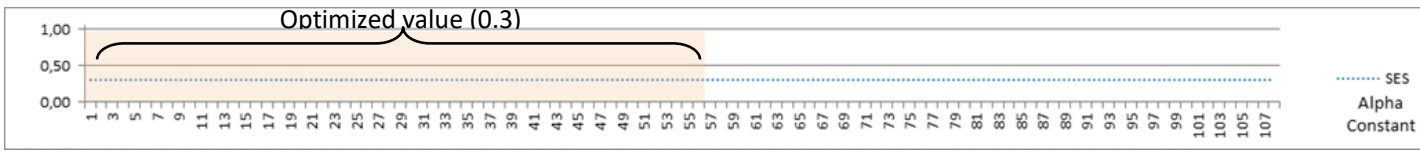

(e)

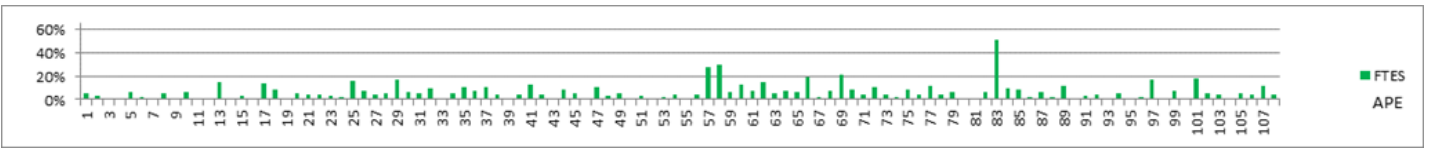

(f)

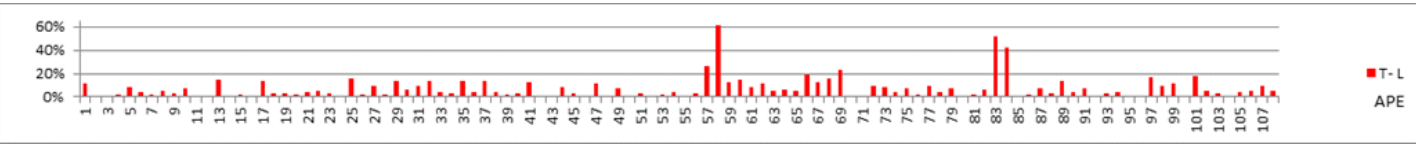

(g)

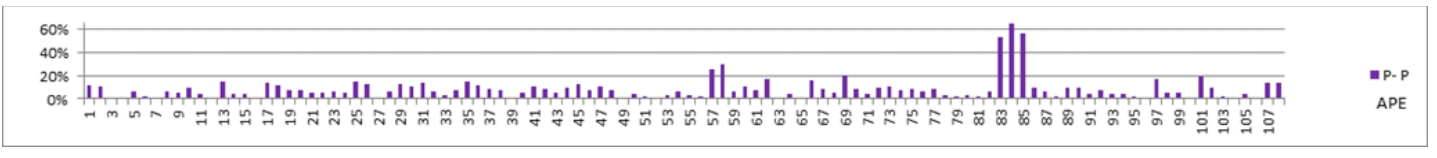

(h)

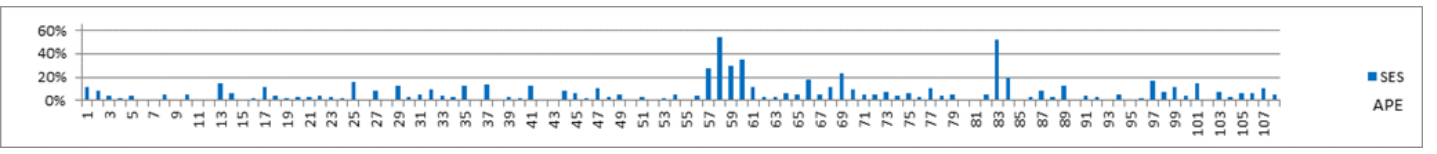

(i)

Figure 5: (a): Comparative forecasts produced by all methods named as FTES, T-L, P-P and SES, respectively. These forecasts are carried out for level shift and level shift with outlier deflection cases in the series, (b): Smoothing parameter $\alpha_{t}$ changes for the FTES method, (c): Smoothing parameter $\alpha_{t}$ changes for the T-L method, (d): Smoothing parameter $\alpha_{t}$ changes for the P-P method, (e): Optimized and fixed smoothing parameter $\alpha$ for SES method for the whole series and this value obtained using the past data of up to 56 points, (f): Absolute percentage error (APE) changes at each forecast point for the FTES method, (g): APE changes at each forecast point for the T-L method, (h): APE changes at each forecast point for the P-P method, (i) : APE changes at each forecast point for the SES method. 


\subsection{Statistical validation}

The statistical evaluation and benchmark of the proposed method is demonstrated by using two criteria, namely the MAPE and the RMSE. The evaluations are carried out on two parts of the series for before and after the level shift point. The statistical results of level shift only and level shift with outlier deflection cases are given in Table 1 , separately.

$$
\begin{gathered}
M A P E=\frac{1}{T} \sum_{t=1}^{T}\left|\frac{e_{t}}{S_{t}}\right| \\
R M S E=\sqrt{\frac{1}{T} \sum_{t=1}^{T} e_{t}^{2}}
\end{gathered}
$$

Where, $e_{t}=S_{t}-F_{t}$, corresponds to $(t)$ and $T$ is the number of forecast.

For all methods, the MAPE and RSME rates are close to each other before level shift, but FTES method has a slightly better result than the other adaptive methods as shown in Table 1. Actual major advantage of the FTES method can be observed after the level shift and/or outlier deflection. The proposed method, FTES produces better results compared to the other methods for the first case (level shift only). The percentage MAPE result belonging to FTES method is determined as $6.24 \%$ for the whole series in the first case while it is determined as $6.71 \%$ for the T-L method and as $7.34 \%$ for the P-P method. For the second case, the increases of the percentage MAPE and RMSE levels are expected due to the outlier deflection in the series. However, the minimum increases of these values are observed for the FTES method. The difference of percentage MAPE values between first and second cases after the level shift is determined as $0.55 \%$ for the FTES method while it is determined as $1.48 \%$ for the T-L method and as $3.22 \%$ for the P-P method. These results clearly reveal that the proposed method, FTES is particularly appropriate for the time series comprising level shift, outlier deflection or both of them.

\section{Conclusion}

In this paper, a new adaptive exponential smoothing method, FTES is introduced for the short-term forecasts. FTES method uses the fuzzy logic approach to set the smoothing factor adaptively depending on the variance changes of the time series. In this context, the new method is more advantageous in

\begin{tabular}{|c|c|c|c|c|c|c|c|c|}
\hline \multirow{3}{*}{ Methods } & \multicolumn{4}{|c|}{$\begin{array}{l}\text { Case } 1 \\
\text { Level shift only }\end{array}$} & \multicolumn{4}{|c|}{$\begin{array}{l}\text { Case } 2 \\
\text { Level shift with outlier deflection }\end{array}$} \\
\hline & \multicolumn{2}{|c|}{$\begin{array}{l}\text { Before level shift } \\
\text { (up to point 56) }\end{array}$} & \multicolumn{2}{|c|}{$\begin{array}{l}\text { After level shift } \\
\text { (from } 56 \text { to } 108 \text { ) }\end{array}$} & \multicolumn{2}{|c|}{$\begin{array}{l}\text { Before level shift } \\
\text { (up to point } 56 \text { ) }\end{array}$} & \multicolumn{2}{|c|}{$\begin{array}{l}\text { After level shift } \\
\text { (from } 56 \text { to 108) }\end{array}$} \\
\hline & MAPE & RMSE & MAPE & RMSE & MAPE & RMSE & MAPE & RMSE \\
\hline FTES & $4.96 \%$ & 33.651 & $7.62 \%$ & 51.042 & $4.96 \%$ & 33.651 & $8.17 \%$ & 86.101 \\
\hline T-L & $5.02 \%$ & 35.607 & $8.54 \%$ & 57.959 & $5.02 \%$ & 35.607 & $10.02 \%$ & 96.880 \\
\hline P-P & $6.79 \%$ & 40.834 & $7.94 \%$ & 52.750 & $6.79 \%$ & 40.834 & $11.16 \%$ & 119.455 \\
\hline SES & $4.78 \%$ & 33.830 & $9.12 \%$ & 59.741 & $4.78 \%$ & 33.830 & $9.96 \%$ & 92.695 \\
\hline
\end{tabular}

Table 1: The statistical results of level shift and level shift with outlier deflection cases. terms of simplicity and applicability compared with many existing methods in the literature.

The validity of the proposed method is illustrated by using the data of M2-Competition time series. The FTES method is successful in improving the forecast accuracy, especially for the time series including level shift or level shift with outlier deflection. The method identifies outlier deflection in the series and it is isolated for the next forecast. The response rate of the method corresponding to the significant changes of the series is satisfactory. The success rates of the FTES method generally condense within a range between $5 \%-15 \%$ on the basis of MAPE results for various time series pattern compared to the other non-adaptive and adaptive methods specified in this study.

However, a limitation exists despite the advantages of the proposed method. If the number of data set is less, the averages of the variance-sensitive variable $\overline{\varphi_{t}}$ may fluctuate. In such cases, a fixed optimal variable $\overline{\varphi_{\mathrm{t}}}$ can be chosen for the first few forecasts until it becomes stable.

\section{References}

[1] Weron R. "Electricity price forecasting: A review of the state-of-the-art with a look into the future". International Journal of Forecasting, 30(4), 1030-1081, 2014.

[2] Göb R, Kristina L, Antonio P. "Electrical load forecasting by exponential smoothing with covariates." Applied Stochastic Models in Business and Industry, 29(6), 6296452013.

[3] Dahiya RC, Alan JG. "Adaptive exponential smoothing Reliability, 23(5), 332-334, 1974.

[4] Macaira PM, et.al. "Forecasting Brazil's electricity consumption with pegels exponential smoothing techniques". IEEE Latin America Transactions, 14(3), 1252-1258, 2016.

[5] Christodoulos C, Christos M, Dimitris V. "On the combination of exponential smoothing and diffusion forecasts: An application to broadband diffusion in the OECD area". Technological Forecasting and Social Change, 78(1), 163-170, 2011.

[6] Trigg DW, Leach AG. "Exponential smoothing with an adaptive response rate". Operational Research Quarterly, 18(1), 53-59 (1967).

[7] Williams DW, Miller D. "Level-adjusted exponential smoothing for modeling planned discontinuities". International Journal of Forecasting, 15(3), 273-289, 1999 models for reliability estimation". IEEE Transactions on 
[8] Monfared MAS, Ghandali, R, Esmaeili M. "A new adaptive exponential smoothing method for non-stationary time series with level shifts". Journal of Industrial Engineering International, 10(4), 209-216, 2014.

[9] Taylor JW. "Smooth transition exponential smoothing". Journal of Forecasting, 23(6), 385-404, 2004.

[10] Fildes R. "Quantitative forecasting-the state of the art: extrapolative models". Journal of the Operational Research Society, 30(8), 691-710, 1979.

[11] Makridakis S, et.al. "The accuracy of extrapolation (time series) methods: Results of a forecasting competition". Journal of Fore-casting, 1(2), 111-153, 1982.

[12] Chow WM. "Adaptive control of the exponential smoothing constant". Journal of Industrial Engineering, 16(5), 314-317,1965.

[13] Roberts SD, Reed Jr. R. "The development of a selfadaptive forecasting technique". AIIE transactions, 1(4), 314-322, 1969.

[14] Mentzer JT, Gomes R. "Further extensions of adaptive extended exponential smoothing and comparison with the M-Competition". Journal of the Academy of Marketing Science, 22(4), 372-382, 1994.

[15] Mentzer JT. "Forecasting with adaptive extended exponential smoothing". Journal of the Academy of Marketing Science, 16(3), 62-70, 1988.

[16] Whybark DC. "Comparison of adaptive forecasting techniques". Logisics and Transportation Review, 8, 13-26, 1973.

[17] Dennis JD. "A performance test of a run-based adaptive exponential smoothing". Production and Inventory Management, 19, 43-46, 1978.

[18] Rao AG, Shapiro A. "Adaptive smoothing evolutionary spectra". Management Science, 17(3), 208-281, 1970.

[19] Pantazopoulos SN, Pappis CP. "A new adaptive method for extrapolative forecasting algorithms". European Journal of Operational Research, 94(1), 106-111, 1996.
[20] Gardner ES. "Exponential smoothing: The state of the art-Part II". International Journal of Forecasting, 22(4), 637-666, 2006.

[21] Taylor JW. "Volatility forecasting with smooth transition exponential smoothing". International Journal of Forecasting, 20(2), 273-286, 2004.

[22] Sudheer G, Suseelatha A. "Short term load forecasting using wavelet transform combined with holt-winters and weighted nearest neighbor models". International Journal of Electrical Power \& Energy Systems, 64, 340-346, 2015.

[23] Bermúdez JD, Segura JV, Vercher E. "A decision support system methodology for forecasting of time series based on soft computing". Computational statistics \& data analysis, 51(1), 177-191, 2006.

[24] Wang J, Zhang W, Wang J, Han T, Kong L. "A novel hybrid approach for wind speed prediction". Information Sciences, 273, 304-318, 2014.

[25] Vroman P, Happiette M, Rabenasolo B. "Fuzzy Adaptation of the Holt-Winter Model for Textile Sales-forecasting". Journal of the Textile Institute, 89(1), 78-89, 1998.

[26] Chan KY, Dillon TS, Singh J, Chang E. "Neural-networkbased models for short-term traffic flow forecasting using a hybrid exponential smoothing and LevenbergMarquardt algorithm". Intelligent Transportation Systems, IEEE Transactions on, 13(2), 644-654, 2012.

[27] Park H, James WM, David AB. "Price dynamics among US electricity spot markets". Energy Economics, 28(1), 81-101, 2006.

[28] Lu X, Dong ZY, Li X. "Electricity market price spike forecast with data mining techniques". Electric Power Systems Research, 73(1), 19-29, 2005.

[29] Mount, TD, Yumei N, Xiaobin C. "Predicting price spikes in electricity markets using a regime-switching model with time-varying parameters". Energy Economics, 28(1), 62-80, 2006.

[30] M2-Competition Time Series Data. "International Institute of Forecasters". https://forecasters.org (31.12.2015). 